\title{
Resistência e queda do TECPAR (1940-1984)
}

\author{
Vanessa Lazarin de Souza ${ }^{1}$
}

- Enviado em 30/09/2017

- Aprovado em 08/12/2017

\section{As bases iniciais do Tecpar (1940 a 1961)}

O Laboratório de Análises e Pesquisa (LAP) foi criado em 02/02/1940 pelo interventor de Getúlio Vargas no Paraná, Manoel Ribas², iniciando suas atividades sete meses depois. Seu idealizador Marcos Augusto Enrietti, filho dos imigrantes italianos Carlos Andrea Enrietti e Antonietta Domenica Chiabotti, era veterinário do Ministério da Agricultura e professor da área na Universidade do Paraná, onde se se graduou no ano de 1937 em veterinária. Se formou também em agronomia pela École d'Agriculture Defumade na França, em 1929 (BRAND, 1991, p. 19). Foi nomeado diretor da instituição que nasceu da necessidade de acelerar o crescimento do Paraná num momento de grande expansão da agricultura no estado. Enrietti acreditava ser essencial a autonomia do Paraná em atender às suas próprias demandas de análises e estudos agrícolas (LUNARDI, 1993, p. 83).

Enrietti participou da resistência paulista contra Vargas em 1932, mesma época em que sua mãe Anita, viúva já há muitos anos, se casou com Manoel Ribas (BRAND, 1991, p. 19). A relação de parentesco entre Enrietti e Ribas é peça essencial na história do Tecpar. Aqui as típicas relações de favoritismo e patronagem do nepotismo (OLIVEIRA, 2012, p. 73) são usualmente atreladas ao desenvolvimento de uma instituição pública.

Com o total apoio de Ribas, o LAP teve então, em 1941, suas atividades ampliadas e começou a prestar serviços especializados. Passa então a se chamar Instituto de Biologia Agrícola e Animal (IBAA). Um ano depois, novamente com o suporte de Manoel Ribas e a chegada de pesquisadores de renome à

\footnotetext{
1 Estudante do curso de Engenharia de Computação na Universidade Tecnológica Federal do Paraná (UTFPR). E-mail: vanessa.2011@alunos.utfpr.edu.br

${ }^{2}$ Interventor de Getúlio Vargas no Paraná entre 1932 e 1945. Nasceuem Ponta Grossa em 1873 numa família histórica da classe dominante do estado, iniciou sua vida política como prefeito de Santa Maria (RS), onde começa a travar relações com Vargas. Sua administração foi marcada por obras de infraestrutura e modernização do maquinário do estado sem se distanciar da política de repressão aos "inimigos do regime" (OLIVEIRA, 1997).
} 
instituição, passa a atender por Instituto de Biologia e Pesquisas Tecnológicas (IBPT), nome que carregou até 1978.

A princípio a estreita ligação com o governo traria força à instituição, mas se mostraria um obstáculo para a continuidade da concepção institucional de Enrietti, especialmente após a saída de seu padrasto do governo em 1945. Assim entra em cena a Fundação Rockefeller ${ }^{3}$, cujo histórico com a Tecpar data de 1950, quando Harry Miller, durante a II Reunião Anual da Sociedade Brasileira para o Progresso da Ciência, visita as instalações do IBPT em Curitiba (BRAND, 1991). Em 1951 o IBPT é transformado numa entidade autárquica, e no mesmo ano recebe US\$40.0000 da fundação para aparelhamento das novas divisões de Biologia Animal, Vegetal e Patologia Experimental. Nos anos seguintes a fundação financia pósgraduações em instituições no exterior para vários pesquisadores do instituto e concede diversos auxílios sendo firmada a parceria - que surge da necessidade de afrouxar a dependência do IBPT de verbas governamentais - oficialmente em 1955.

\section{Equipe que iniciou os trabalhos no Laboratório de Análises e Pesquisas - LAP em 1940: Marcos Augusto Enrietti (1), Dulcídio Lacerda (2), Reinaldo Krause Spitzner (3) e Oscar Krebs Palmquist (4).}

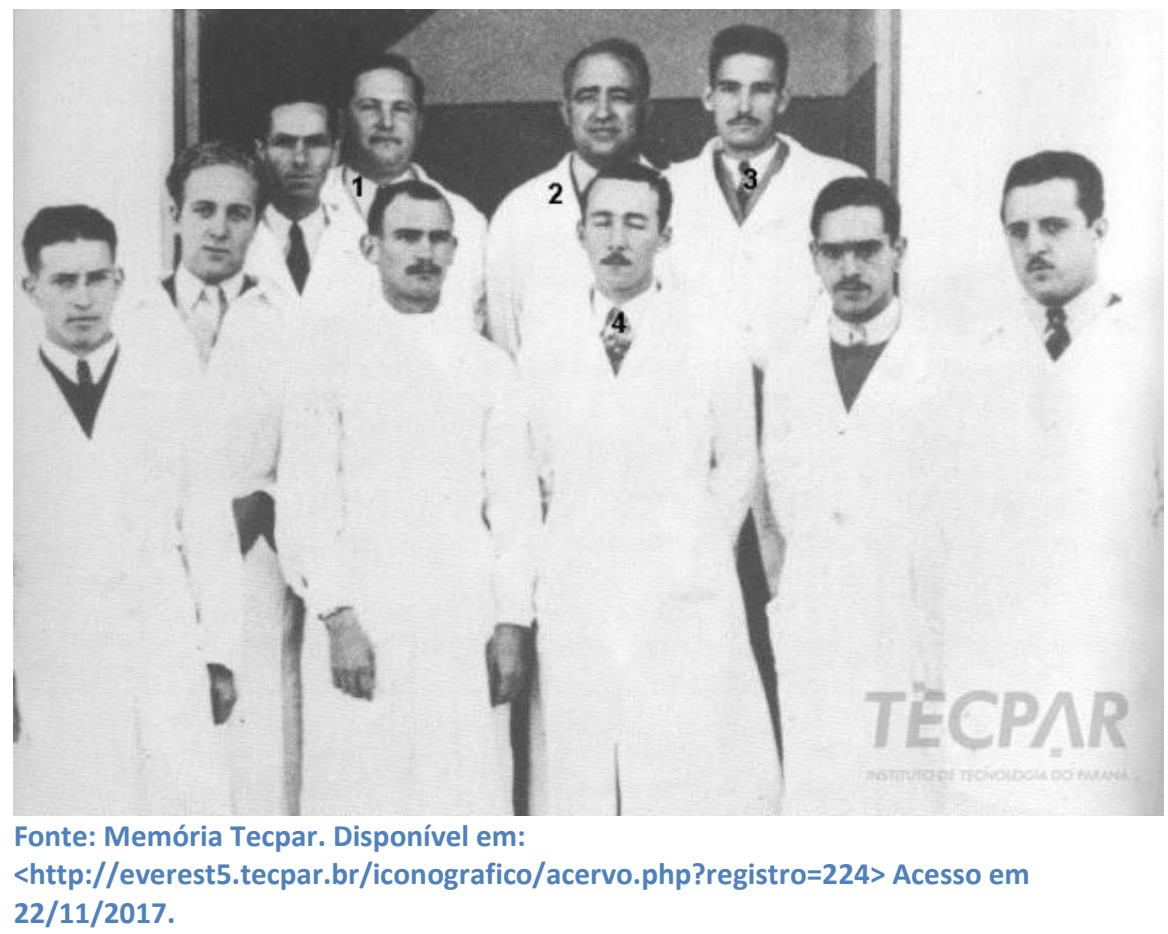

As

inconstâncias das verbas governamentais dirigidas à instituição, intimamente ligadas às movimentações e

\footnotetext{
3 Fundação norte-americana criada em 1913 que segundo seu site "visa melhorar a saúde pública e estimular a pesquisa no exterior". A Fundação Rockefeller financiou muitos projetos e obras no Brasil, entre elas a construção do Hospital das Clínicas de São Paulo em 1944 (ROCKEFELLER, 2017).
} 
crises políticas do país, tiveram pouco ou nenhum impacto no seu desenvolvimento devido à aliança do IBPT com a fundação Rockefeller (especialmente no âmbito financeiro) e principalmente à desenvoltura de Enrietti - que habilmente usava seu capital político e social a favor do IBPT, especialmente de sua relação familiar com Manoel Ribas. Entre sua criação e 1961 o IBPT ganhou novas instalações em Curitiba, abriu laboratórios em Jacarezinho (1945), expandiu suas funções (inclusive executando serviços antes designados ao Departamento de Agricultura), criou novos departamentos e seu próprio periódico de divulgação científica, entre outros feitos (LUNARDI, 1993).

Em 1961 toma posse o governador Ney Braga ${ }^{4}$, com quem Enrietti já acumulava certa animosidade pela sua candidatura à ALEP em 1958 pelo Partido Social Progressista (PSP). Mesmo sem vitória a candidatura pela oposição afeta os ânimos e angaria a Enrietti muitos inimigos. Enrietti é então afastado do IBPT e os rumos da instituição se tornam incertos.

\section{O fim da era Enrietti (1961 a 1984)}

Com a saída de Enrietti em 1961 o IBPT ficou mais suscetível às oscilações políticas do Brasil. O governo de Ney Braga visava modernizar a estrutura político-econômica e social do Estado, assim as atividades de pesquisa do IBPT, que muitas vezes não tinham aplicação direta, foram secundarizadas. Suas instalações passaram a ser ocupadas por outros órgãos públicos e com o decreto de 1963 houve uma ampla reforma organizacional de caráter imediatista e pragmático. O cerceamento do IBPT causou a saída gradual de seus pesquisadores para a Universidade - ambiente mais seguro e propício à pesquisa - e o cancelamento do convênio entre esta e o IBPT em 1964 (LUNARDI, 1993, p. 198).

Foi um período de grande instabilidade política no país e isso se refletiu dentro da instituição, com administrações breves e que "pouca força tiveram para assegurar recursos em volume suficiente à expansão das linhas de pesquisa ou sequer manter os níveis anteriores" (BRAND, 1991, p. 76). Nos três anos seguintes a instituição foi dirigida por Astolpho Macedo Souza5(1961), Ivan Austragésilo Maída6 (19611963) e Nelson Arthur Costa $^{7}$ (1963-1966). A nível federal, o quadro para o golpe militar começa a se

\footnotetext{
4 O militar Ney Braga assume o governo do estado entre 1961 e 1965 e posteriormente entre 1979 e 1982 . É introduzido à vida política por seu cunhado Bento Munhoz da Rocha Neta - governador do Paraná entre 1951 e 1955 - e é eleito prefeito de Curitiba em 1954. Em sua trajetória política também ocupou cargos como deputado federal, ministro e senador (KUNHAVALIK, 1999).

${ }^{5}$ Astolpho Macedo Souza era veterinário no IBPT e dirigiu a instituição por apenas um mês.

6 Ivan Austragésilo Maída foi pesquisador na área de química do IBPT. Durante sua gestão o desentendimento entre os pesquisadores da Divisão de Patologia se agravou devido às suas diferentes orientações institucionais (LUNARDI, 1993).
}

${ }^{7}$ Nelson Arthur Costa era engenheiro químico do IBPT. 
formar. O presidente João Goulart ocupava o cargo num clima de incertezas, aceitando a contragosto a emenda parlamentarista. Propõe diversas reformas de base e aumenta o salário mínimo em 100\% numa tentativa de voltar-se aos trabalhadores, mas a história já caminhava para outro desfecho (HELLER, 2000).

A falta de liderança e de uniformidade de seus dirigentes, somada às mudanças de competências pelo governo estadual, fez o IBPT perder seus mais importantes laços com a comunidade científica nacional. Em 1964 acontece a tomada pela Secretaria de Agricultura do prédio construído especificamente para a Divisão de Patologia Experimental do IBPT. A castração simbólica, porém explícita foi feita a marretadas que destruíram mesas, equipamentos, salas, tubulações e paredes do prédio (LUNARDI, 1993, 199).

Em 1966 o descaso do governo com o instituto chegou a tal ponto que o jornal " Diário do Paraná" publicou uma série de seis reportagens intitulada "Do cérebro para as gavetas" ${ }^{8}$, onde criticava incisivamente a "desatenção dada à ciência no Paraná e no Brasil". Ainda em 1966 o diretor Nelson Arthur Costa declarava que "a fase negra do IBPT tinha passado", porém a "castração" institucional continuou com o primeiro edifício construído para o IBPT, em 1940, sendo cedido para Fundação Educacional do Paraná (FUNDEPAR). Todas as coleções botânicas, minerais, fitopatológicas e entomológicas da instituição foram consideradas "entulhos" e muitas delas foram perdidas durante as décadas de 60 e 70 (LUNARDI, 1993).

Muitos outros dissabores ainda recaem sobre o IBPT nas décadas de 60 e 70. Em dezembro de 1978 o "Instituto se desfaz das tradicionais linhas de pesquisa em patologia animal e vegetal, concentrando-se na produção de vacinas e antígenos" (BRAND, 1991, p. 78). No ano seguinte o Tecpar é instituído e o IBPT extinto por decreto.

Alguns anos depois o Tecpar recebe uma proposta por parte de agências oficiais japonesas e firma contrato com estas para desenvolver pesquisas e prestar serviços à indústria, especialmente nas áreas de eletrônica e mecânica, com a inauguração do CTI - Centro de Tecnologia Industrial Brasil-Japão do Paraná em 1983, quase coincidindo com o fim do regime militar, inaugurando uma nova fase da instituição.

\section{O nepotismo "bonzinho" do Tecpar}

Oliveira (2012) afirma que "as conexões entre estruturas de parentesco e estruturas de poder político geram o fenômeno do nepotismo" (p. 81). Também aponta que essas são variáveis em sua extensão e abrangência, que atravessam os poderes do Estado e conectam suas diferentes funções. A

\footnotetext{
${ }^{8}$ As reportagens assinadas por Ariovaldo Kuntze e publicadas no periódico "Diário do Paraná", 1966, eram: 1) "Descaso do IBPT torna ciência inútil no Paraná; 2) "Ouvidos fechados ante os sulcos abertos pela erosão"; 3) "Teses de 30 anos previram um novo nordeste no Paraná"; 4) "Frustrados esforços para calagem dos nossos solos"; 5) "Pérola da terra ameaça viticultura paranaense"; 6) "Ignorados recursos minerais do Paraná".
} 
criação da Tecpar não poderia ser um exemplo mais explícito desse fenômeno. Seu primeiro presidente, Marcos Augusto Enrietti, era enteado do então interventor do Paraná Manoel Ribas - que por sua vez tinha uma relação bastante privilegiada e pessoal com Getúlio Vargas graças a seu histórico na política do Rio Grande do Sul - e usou, e muito, desse parentesco para favorecer o Tecpar. Fugindo a regra, nesse caso o nepotismo foi para "o bem". Enrietti tinha de fato todo o conhecimento técnico necessário para exercer a função de presidente de tal instituição, e o Paraná precisava de uma entidade de pesquisa que favorecesse o crescimento do estado.

A importância dessas conexões fica ainda mais clara quando vemos como as relações de Enrietti com o governo mudaram com a saída de Ribas em 1945. Seus laços em diferentes esferas do governo eram mais fortes, mas esmaeceram com as constantes crises políticas da época, sendo a "gafe" de 1958 (quando se candidatou à ALEP) um catalisador. Ainda assim habilmente ele procurou outros caminhos para manter o IBPT no rumo planejado, e por 20 anos a instituição evoluiu sob sua presidência.

Após as administrações de Astolpho Macedo Souza, Ivan Austragésilo Souza e Nelson Arthur Costa seguem-se as administrações de Rolando Salin Zappa Mansur (1966-1968) e do engenheiro agrônomo Ubiratan Pompeo Sá (1968-1969), que foi parte da diretoria regional da Arena, pouco antes de ocupar a diretoria do Tecpar. De 1969 a 1971 temos Alsedo Leprevost, anteriormente ligado à Divisão de Mineralogia e logo após o engenheiro químico Dinor Olegário Voss entre 1971 e 1983 - que anteriormente foi bolsista da Fundação Rockefeller e trouxe novas tecnologias na área de instrumentação da Universidade da Pennsylvania (EUA) ao IBPT nos anos 50. O último presidente do período estudado foi Edmundo Reichmann, entre 1983 e 1988.

Tabela 1: Presidentes da Tecpar de sua criação até 1988.

\begin{tabular}{|c|c|c|}
\hline Período & Presidente & Parentes na política \\
\hline $1940-1961$ & Marcos Augusto Enrietti & Sim \\
\hline $1961-1961$ & Astolpho Macedo Souza & \\
\hline $1961-1963$ & Ivan Austragésilo Maída & \\
\hline $1963-1966$ & Nelson Arthur Costa & \\
\hline $1966-1968$ & Rolando Salin Zappa Mansur & \\
\hline $1968-1969$ & Ubiratan Pompeo Sá & Sim \\
\hline
\end{tabular}

\footnotetext{
${ }^{9} \mathrm{O}$ sobrenome Mansur aparece na política paranaense na década de 40, com João Mansur, que foi prefeito de Irati, deputado estadual e governador do estado por 39 dias (GOULART, 2016). Contudo não foi encontrada dados que comprovem o possível parentesco entre João Mansur e Rolando Salin Zappa Mansur.
} 


\begin{tabular}{|c|c|c|}
\hline $1971-1983$ & Dinor Olegário Voss & \\
\hline $1983-1988$ & Edmundo Reichmann & \\
\hline
\end{tabular}

Fonte: Autora.

Mesmo considerando que podem existir laços políticos e familiares não tão óbvios quanto o de Ribas e Enrietti entre membros do governo e outros presidentes do Tecpar percebe-se que estes têm pouco ou nenhum histórico político relevante. Contudo, todos têm bagagem técnica, sendo que muitos deles já eram parte do IBPT antes do começo da ditadura militar, o que disso a de muitos outros órgãos e empresas públicas.

\section{Considerações finais}

O Tecpar fez um uso atípico de redes de nepotismo em sua criação e manutenção, apesar disso é um exemplo muito didático do alcance e do poder desse fenômeno. Contudo na instituição o nepotismo toma forma tal que não traz dano à sociedade como de costume. Observamos como a segurança que Enrietti trazia à instituição graças a seu capital político, fez falta após sua saída no início dos anos 60 , deixando a instituição mais vulnerável às crises políticas do país que se agravaram na mesma época. $\mathrm{A}$ pesquisa sobre os outros presidentes do período e suas redes de influência política e social também merece ser aprofundada, porém foge do escopo do presente trabalho.

Felizmente o Tecpar já era uma instituição bem estabelecida, que mesmo com todas as adversidades causadas por um cenário político instável de décadas sobreviveu - e seu restabelecimento coincide com o declínio do regime ditatorial.

Atualmente é uma respeitada e diversificada instituição de pesquisa, que presta importantes serviços especializados e de pesquisa a todo o Paraná, contando com seis campi e milhares de colaboradores.

\section{Referências}

BRAND, Jaques; ROCHA, Regina. Do IBPT de Marcos Augusto Enrietti ao Tecpar. Curitiba: Cidade e Campo, 1991.

\footnotetext{
${ }^{10}$ Alsedo Leprevost nasceu em 1920, filho de José Leprevost e Angelita Leprevost, irmão de Ney Leprevost, ligado ao Partido Social Democrático (PSD), ocupou cargos de Procurador-Geral do Estado, prefeito de Curitiba, Procurador Fiscal e do Tribunal de Contas. Tio de Luiz Antonio Leprevost e tio-avô de Ney Leprevost, que concorreu a prefeitura de Curitiba em 2016 (PEREIRA, 2016).
} 
GOULART, Monica H. H. Silva. Família Slavieiro: Uma História de Grandes Conquistas. Revista NEP (Núcleo de Estudos Paranaenses), Curitiba, no 2, v. 2, p. 720-735, 2006.

Assembleia Legislativa do Paraná: perfil parlamentar e relações de parentesco (1935-1962). 213 f. Projeto de Pesquisa relativo ao Estágio de Pós-Doutorado em Sociologia, Universidade Federal do Paraná, Curitiba, 2016.

HELLER, Milton Ivan; DUARTE, Maria L. A. González. Memórias de 1964 no Paraná. Curitiba: Imprensa Oficial, 2000.

KUNHAVALIK, José Pedro. Ney Braga: Trajetória política e bases do poder. 1999. Dissertação (Mestrado em Sociologia Política) - Universidade Federal de Santa Catarina, Florianópolis.

LUNARDI, Maria Elizabeth. Organização da Ciência no Paraná: a contribuição do IBPT. Curitiba: Tecpar/Banestado, 1993.

OLIVEIRA, Ricardo Costa. Notas sobre a política paranaense no período de 1930 a 1945. Revista de Sociologia e Política, Curitiba, no 9, p. 47-56, 1997.

Na teia do nepotismo. Curitiba: Insight, 2012.

PEREIRA, Fernando Marcelino. Ney Leprevost (PSD), herdeiro das velhas oligarquias, 2016. Disponível em <https://www.brasildefato.com.br/2016/09/22/artigo-ney-leprevost-psc-herdeiro-das-velhasoligarquias/>. Acesso em 27/11/2017.

AYUSO, Silvia. O poder e a tragédia dos Rockefeller, 2014. Disponível em: <https://brasil. elpais.com/brasil/2014/06/20/sociedad/1403287058_345251.html>. Acesso em: 05/11/2017.

CHIAVENATO, Júlio José. O golpe de 64 e a ditadura militar. São Paulo: Moderna, 1994.

CZESLUNIAK, Adriana. Lista de falecimentos, 2009. Disponível em <http://www.gazetadopovo.com.br/servicos/falecimentos/lista-de-falecimentosbyhge69uam9vpgu6ocp0saxce>. Acesso em 27/11/2017.

ROCKEFELLER FOUNDATION, 2017. <https://www.rockefellerfoundation.org/>. Acesso em 30/10/2017.

TECPAR. Memória Tecpar. <http://everest5.tecpar.br/iconografico/>. Acesso em 30/10/2017.

Nota de falecimento: morre aos 88 anos ex-presidente do Tecpar Dinor Voss, 2016. <http://portal.tecpar.br/noticia/nota-de-falecimento-morre-aos-88-anos-ex-presidente-do-tecpar-dinorvoss/>. Acesso em: 30/10/2017. 20/10/207.

Sobre o Tecpar, 2017. Disponível em: <http://portal.tecpar.br/sobre-o-tecpar/>. Acesso em 